\title{
Canadian Geotechnical Journal — Editors' Choices 2019
}

The Editor's Choice initiative by Canadian Science Publishing and the Canadian Geotechnical Journal is a means of highlighting articles of particularly high caliber and topical importance. Last year, the following papers were featured on the Journal's home page.

In situ evaluation of performance of reclamation measures implemented on abandoned reactive tailings disposal site Marie-Pier Ethier, Bruno Bussière, Michel Aubertin, Abdelkabir Maqsoud, Isabelle Demers, and Stefan Broda 55(12): 1742-1755 dx.doi.org/10.1139/cgj-2016-0699

Time-dependent behaviour of sand with different fine contents under oedometric loading Friedrich Levin, Stefan Vogt, and Roberto Cudmani 56(1): 102-115 dx.doi.org/10.1139/cgj-2017-0565

Axial load testing of helical pile groups in glaciolacustrine clay Stephen A. Lanyi-Bennett and Lijun Deng 56(2): 187-197 dx.doi.org/10.1139/cgj-2017-0425

Mechanical behaviour of Panzhihua iron tailings W. Li and M.R. Coop 56(3): 420-435 dx.doi.org/10.1139/cgj-2018-0032

Assessment of reliability-based design of stable slopes Nico de Koker, Peter Day, and Andrew Zwiers 56(4): 495-504 dx.doi.org/10.1139/cgj-2018-0149

Colloid effect on clogging mechanism of hydraulic reclamation mud improved by vacuum preloading Yongfeng Deng, Li Liu, Yu-Jun Cui, Qi Feng, Xianglong Chen, and Ning He 56(5): 611-620 dx.doi.org/10.1139/cgj-2017-0635

Reliability-based design of internal limit states for mechanically stabilized earth walls using geosynthetic reinforcement Richard J. Bathurst, Peiyuan Lin, and Tony Allen 56(6): 774-788 dx.doi.org/10.1139/cgj-2018-0074

Axial and radial thermal responses of energy pile under six storey residential building Mohammed Faizal, Abdelmalek Bouazza, John S. McCartney, and Chris Haberfield 56(7): 1019-1033 dx.doi.org/10.1139/cgj-2018-0246

Calibration of resistance factors for geotechnical seismic design Farzaneh Naghibi and Gordon A. Fenton 56(8): 1134-1141 dx.doi.org/10.1139/cgj-2018-0433

Kinematic energy balance approach to submarine landslide evolution Christian Buss, Balz Friedli, and Alexander M. Puzrin 56(9): 1351-1365 dx.doi.org/10.1139/cgj-2017-0651

Triaxial stress path tests on artificially prepared analogue alpine permafrost soil Yuko Yamamoto and Sarah M. Springman 56(10): 1448-1460 dx.doi.org/10.1139/cgj-2017-0737

Determination of efficient sampling locations in geotechnical site characterization using information entropy and Bayesian compressive sampling

Tengyuan Zhao and Yu Wang

56(11): 1622-1637 dx.doi.org/10.1139/cgj-2018-0286 